\title{
Blending teaching strategies to improve nursing students' clinical judgment abilities
}

Imad Hasan Alfayoumi*

Isra University, Amman, Jordan

Received: December 14, 2018

Accepted: January 16, 2019

Online Published: February 25, 2019

DOI: $10.5430 /$ cns.v7n2p54

URL: https://doi.org/10.5430/cns.v7n2p54

\begin{abstract}
Background: Nursing educators need to determine educational strategies that will enable nursing students to reach effective and timely clinical judgments. Aim: This study documents how a combination of the constructivist approaches of concept-based learning and concept mapping impacts nursing students' clinical judgment skills.

Methods: The study utilized a pretest post-test design to collect data from a convenient sample of all students who commenced adult health nursing courses at a private university in Jordan $(N=40)$. An observation of the performance aspects of clinical judgment of engagement, background, process, and representation utilizing a four-point Students Performance Aspects of Clinical Judgment Scale (SPACJS) was performed.

Results: Except for the engagement aspect, all other aspects of clinical judgment showed significant improvements by the end of the courses. Moreover, overall clinical judgment ability significantly improved as the courses concluded.

Conclusion: When the SPACJS and the constructivist approaches are respectively institutionalized as a clinical evaluation tool and as teaching strategies, students will receive specific feedback that will subsequently improve their engagement, background, process, and representation of future clinical judgment encounters. This feedback is relevant to specific concepts and cognitive maps will help students synthesize mental criteria against which future clinical encounters are reflected. As a result, students contextual clinical judgment maturity will be enhanced.
\end{abstract}

Key Words: Clinical judgment, Concept-based learning, Concept mapping, Nursing students

\section{INTRODUCTION}

With current global nursing shortages and understaffing, ${ }^{[1-4]}$ and increased patient acuity levels in dynamic and complex health care systems, contemporary nursing practice needs effective thinkers and decision makers. ${ }^{[5,6]}$ These skills should be established early in undergraduate students ${ }^{[7]}$ to enable them to develop the systematic and logical thought processes essential for the delivery of safe and optimal nursing care ${ }^{[8]}$ Among these processes is the clinical judgment activity whereby a dilemma is identified and corrected. ${ }^{[9]}$
Petrina ${ }^{[10]}$ acknowledged four aspects or skills of this activity, namely, engagement, background knowledge, process, and representation.

Research has highlighted that $70 \%$ of novice nurses were inadequately prepared to make safe, effective decisions at the time of patient deterioration. ${ }^{[11]}$ Moreover, Saintsing et al. ${ }^{[12]}$ indicated that between $49 \%$ and $53 \%$ of novice nurses with less than one year of clinical experience are involved in errors in nursing care. This might be attributed to novices experiencing a feeling of unpreparedness in undertaking clinJordan. 
ical judgments, which subsequently impacts their recruitment and retention. ${ }^{[13]}$ Similarly, Doody et al. ${ }^{[14]}$ highlighted that new nursing graduates in Ireland are lacking confidence in their knowledge and ability to make clinical judgments. A Middle Eastern report was comparable with the previous findings and indicated that the majority of newly licensed nurses were lacking clinical judgment abilities essential for competent practice. ${ }^{[15]}$

In facing these challenges, nursing educators in undergraduate nursing programs need to determine educational strategies that will enable nursing students to reach effective, timely clinical judgments. ${ }^{[16-18]}$ Combining instructional methods into nursing programs can be an effective means of enhancing students' clinical judgment skills. Concept-based learning $[16,17,19]$ and concept mapping ${ }^{[16,17,20]}$ are among the many constructivist approaches recognized as effective tools in sharpening students' mental abilities. Concept-based learning is a contemporary clinical teaching tool that prevents the problems of content saturation, repetition, and fragmentation between classroom knowledge and clinical experiences. ${ }^{[21]}$ Students' patient care assignments are structured around the basic concepts elemental for tailoring nursing care to individual patients. These experiential learning activities will facilitate knowledge gain and deep thinking. ${ }^{[22]}$ Patient safety, oxygenation, and pain management are examples of clinical concepts that will formulate the mental criteria to judge subtle cues relevant to patient care. ${ }^{[19]}$ Concept based learning impacts what the student brings to the situation ${ }^{[16]}$ and directs students towards noticing significant cues relevant to the attained concepts being integrated into future nursing care. ${ }^{[23]}$ These processes will help bridge the theory-practice gap and enhance the development of clinical judgment. ${ }^{[24]}$ The strategy will also help students analyze patient data, construct knowledge, and think faster to resolve problems as confidence is built in students. ${ }^{[25]}$

Concept mapping was originally developed to promote critical thinking. ${ }^{[26]}$ It is a teaching strategy that facilitates higherorder thinking skills in a variety of learning domains. ${ }^{\text {[27] }}$ The process of implementing concept mapping includes the assimilation of new concepts in circles or boxes and then creating hierarchical arrangements between concepts and sub-concepts. The map is then completed by tying relational concepts with each other using arrows or lines. ${ }^{[28]}$ Evidence supports the use of concept mapping to enhance students' clinical judgment abilities. ${ }^{[29]}$

Moving away from single traditional pedagogies towards blended teaching strategies can contribute to the enhancement of nurses' clinical judgment. ${ }^{[30]}$ Research shows that student learning can be enhanced whenever concept learning strategies are coupled with other strategies. ${ }^{[25]}$ Therefore, Published by Sciedu Press this inaugural study, as part of a comprehensive project on nursing curriculum reform, aims at exploring the effect of blending constructivist pedagogies with aspects of nursing students' clinical judgment. The results of this study will inform the curriculum reform project of the benefits of continuing to introduce the combined pedagogies of concept-based learning and concept mapping to the subsequent courses of the Bachelor of Nursing program.

\section{Research hypothesis}

The study intervention includes utilizing the concept based learning strategy to guide students' clinical training and concept mapping to facilitate the attainment of the theoretical concepts of the Adult Health Nursing course. It is estimated that combining the two pedagogies will positively impact students' clinical judgment as each strategy was proven to be effective. Therefore, this study hypothesizes that aspects of nursing students' clinical judgment performance are enhanced when concept based learning and concept mapping pedagogies are combined throughout adult health nursing courses.

\section{METHOD}

A quasi experimental design was utilized to collect data from the study group of students undertaking an adult health nursing course in the first semester of the academic year 2015. With baseline data obtained at the beginning of the courses and posttest information collected immediately after the intervention, it may be reasonable to infer that introducing the blended pedagogies is the most probable explanation for clinical judgment skill gain. ${ }^{[31]}$ The Transparent Reporting of Evaluations with Non-randomized Designs (TREND) statement checklist for evaluations of behavioral and public health interventions was utilized to report the study findings.

\subsection{Ethical statement}

Scientific and ethical approvals for the study were granted from the University. This inaugural study has two simultaneous wings - one that examined students' clinical reasoning by means of a questionnaire; and the current study that targeted their clinical judgment. Answering the questionnaire implicitly denoted obtained consent from students. The completed observation sheets by students' clinical instructors were coded by a secretary who then submitted them to the researcher for data entry and analysis. The secretary and the clinical instructors have signed confidentiality agreements with the researcher.

The Students Performance Aspects of Clinical Judgment Scale (SPACJS) (see Figure 1) is constructed by the researcher based on bibliographical material ${ }^{[10,32,33]}$ that was acknowledged by the researcher. 


\begin{tabular}{|c|c|c|c|c|}
\hline \begin{tabular}{|lll} 
Aspect of $\mathrm{CJ}$ & Score \\
\end{tabular} & 1 & 2 & 3 & 4 \\
\hline $\begin{array}{l}\text { Engagement: } \\
\text { The extent to which student } \\
\text { identifies something as a } \\
\text { problem \& assertively } \\
\text { becomes engaged in solving } \\
\text { it. }\end{array}$ & $\begin{array}{l}\text { Even in simple, common, or familiar } \\
\text { situations, has difficulty interpreting or } \\
\text { making sense of data; } \\
\text { Patient's problems left unrecognized } \\
\text { and no action was taken. }\end{array}$ & $\begin{array}{l}\text { Confused by the clinical situation \& the } \\
\text { amount and kind of data. As a result, the } \\
\text { student: } \\
\text { - Focuses on one thing at a time \& } \\
\text { missing most deviations; unsure how } \\
\text { to continue the assessment. } \\
\text { - Decides not to get involved in the } \\
\text { situation or withdraws from the scene. }\end{array}$ & $\begin{array}{l}\text { Recognizes most obvious deviations in data } \\
\text { and uses these to continually assess; misses the } \\
\text { most subtle signs. }\end{array}$ & $\begin{array}{l}\text { Assertively recognizes deviations from } \\
\text { expected patterns in assessment data } \\
\text { Assumes responsibility even when facing } \\
\text { complex, contrary, or confusing data by } \\
\text { doing the following: } \\
\text { - Reassessing the patient, } \\
\text { - Reporting findings th the Primary Nurse, or } \\
\text { - Monitoring patient's progress closely. }\end{array}$ \\
\hline $\begin{array}{l}\text { Process: } \\
\text { The extent to which students } \\
\text { knows \& uses appropriate } \\
\text { reasoning strategies (i.e. } \\
\text { analytical \& narrative } \\
\text { reflective) and his/her } C R \text { is } \\
\text { free of biases, which will } \\
\text { result in appropriate } C J \text { and } \\
\text { desired patient's outcomes. }\end{array}$ & $\begin{array}{l}\text { Except in routine situations, is } \\
\text { - Stressed \& disorganized, } \\
\text { - Lacks control, } \\
\text { - Makes patients \& families anxious or } \\
\text { less able to cooperate; } \\
\text { Focuses on developing a single } \\
\text { intervention, addressing a likely } \\
\text { solution, but it may be confusing, } \\
\text { incomplete, and/or inaccurate; } \\
\text { Unable to select and/or perform } \\
\text { nursing skills; } \\
\text { Accompanying rationale is vague, } \\
\text { confusing, and reflects many reasoning } \\
\text { errors; } \\
\text { Even when prompted, decision points } \\
\text { are irrelevant. }\end{array}$ & $\begin{array}{l}\begin{array}{l}\text { Reassures patients and families in } \\
\text { relatively simple situations, but becomes } \\
\text { stressed \& disorganized easily; }\end{array} \\
\begin{array}{l}\text { Develops interventions for simple cases } \\
\text { on the basis of the most obvious data; } \\
\text { unable to make adjustments as indicated } \\
\text { by the patient's response; } \\
\text { Hesitant or ineffective in using } \\
\text { nursing skills; }\end{array} \\
\begin{array}{l}\text { Accompanving rationale indicates a } \\
\text { reasoning error; } \\
\text { Has difficulty imagining alternative } \\
\text { choices. }\end{array} \\
\end{array}$ & $\begin{array}{l}\text { Generally, displays confidence, able to control } \\
\text { or calm most situations; stressed in particularly } \\
\text { complex situations, but able to seek the needed } \\
\text { assistance; reassures patients \& their families; } \\
\text { Develops interventions on the basis of relevant } \\
\text { patient data; monitors progress regularly but } \\
\text { does not expect to have to change treatments; } \\
\text { Displays competence in the use of most } \\
\text { nursing skills (could improve speed or } \\
\text { accuracy); } \\
\text { Accompanying rational shows appropriate } \\
\text { reasoning; } \\
\text { With minimal prompting, key decision points } \\
\text { are identified, and alternatives are considered. }\end{array}$ & $\begin{array}{l}\text { Assumes responsibility and } \\
{[2] \quad \text { Displays leadership \& confidence }} \\
{[2] \quad \text { Able to control \& calm all }} \\
\text { situations; } \\
{[2] \quad \text { Involves team; }} \\
\text { [2] Reassures patients \& their } \\
\text { families and check understanding; } \\
\text { Interventions are tailored for the individual } \\
\text { patient \& all decisions are accurate; } \\
\text { Displays competence in the use of nursing } \\
\text { skills (as per student's scope of practice); } \\
\text { Accompanying rationale shows appropriate } \\
\text { reasoning; } \\
\text { Decision points, elaborating alternatives, \& } \\
\text { accurately evaluating choices against } \\
\text { alternatives. }\end{array}$ \\
\hline $\begin{array}{l}\text { Representation: } \\
\text { How effective the student can } \\
\text { communicate his/her } \\
\text { decision/ solution/CJ \& the } \\
\text { thinking processes behind it. } \\
\text { This includes effective self- } \\
\text { analysis and evaluation. }\end{array}$ & $\begin{array}{l}\text { Has difficulty communicating } \\
\text { Explanations are confusing; directions } \\
\text { are unclear or contradictory; patients \& } \\
\text { families are made confused or anxious } \\
\& \text { are not reassured; } \\
\text { Justifies personal decisions \& choices } \\
\text { without evaluating them and appears not } \\
\text { interested in improving performance or } \\
\text { is unable to do so. } \\
\end{array}$ & $\begin{array}{l}\text { Shows some communication ability } \\
\text { when prompted } \\
\text { Communication with patients, families, } \\
\text { \& team members is only partly } \\
\text { successful, displays caring but not } \\
\text { competence; } \\
\text { Self-protective in evaluating personal } \\
\text { choices; makes some effort to learn } \\
\text { from experiences. } \\
\end{array}$ & $\begin{array}{l}\text { Generally, communicates well (verbally \& in } \\
\text { writing); } \\
\text { Explains carefully to patients, families, \& team } \\
\text { members; could be more effective in } \\
\text { establishing rapport; } \\
\text { Reflects on and evaluates experiences; identify } \\
\text { strengths \& areas for improvement; could be } \\
\text { more effective in evaluating weaknesses. }\end{array}$ & $\begin{array}{l}\text { Communicates effectively; } \\
\text { Explains interventions fully to patients, } \\
\text { families, \& team members; effective in } \\
\text { establishing rapport; } \\
\text { Reflects on nursing experiences; accurately } \\
\text { identifies strengths \& areas for improvement } \\
\text { and develops specific plans to eliminate } \\
\text { weaknesses. }\end{array}$ \\
\hline
\end{tabular}

Figure 1. Students performance aspects of clinical judgment scale

\subsection{The intervention}

While concept mapping pedagogy guided the theoretical aspects of Adult Health Nursing courses, the clinical courses were steered by the concept based learning strategy. The two course coordinators who were responsible for the classroom theoretical courses demanded prerequisite material for the scheduled sessions. Students were required to possess basic pharmacological knowledge relevant to the particular disease pathology. Throughout the ninety-minute session, the first two boxes were used by the coordinator and the students to place the signs and symptoms of the interconnected health problems in them; and then identify the actual or potential problems relevant to nursing practice. The interdisciplinary management modalities were then cascaded to the evaluation aspects of the care planning processes. Hyperthyroidism and hypothyroidism were examples of interconnected problems that were weaved into the same map.

The knowledge base for the concept based learning activities demanded the clinical instructors to outline essential concepts stemming from the Nursing Intervention Classification (NIC) taxonomy. Concepts supporting physical and psychosocial functioning such as activity and exercise; elimination; nutrition; comfort and pain management; fluid, electrolytes, and acid-base balance; drug management; neurological, respiratory, and tissue perfusion management; skin and wound care; perioperative care; thermoregulation; and communication and coping assistance were targets during the clinical weeks. The initial three weeks of clinical course stressed the importance of the safety, risk and information management concepts.

A total of 168 clinical hours distributed over the fourteenweek semester constituted the clinical rotation. Each week targeted one of the previous concepts, which was briefed by the clinical instructor at the beginning of the first day and then debriefed during the post conference at the end of the second clinical day of the week. The assigned adult general cases to individual students were germane to the classroom pathophysiologies. Debriefings demanded the eight students in the clinical group to reflect on both the assessment and the care provided for their assigned patients in relation to the concept of the week. A twenty-minute presentation of the particular concept by a student preceded this narrative reflective activity. The five clinical instructors received relevant training provided by the author to ensure consistency. As the concepts accumulated throughout the semester, students' assessments and discussions became more indepth and more comprehensive.

\subsection{Population and sample}

All students enrolled in one of the two adult health nursing courses (Adult One or Two) were invited by the course co- 
ordinators to participate in the study. The entire group $(\mathrm{N}=$ 40) agreed to participate in the study. Nursing care of adult patients as per body systems are distributed among the two parts of the course. The entire group that formulated a consecutive sample $(\mathrm{N}=40)$ agreed to participate in the study. It was mandated that the theoretical and clinical components of the course were consecutively undertaken by the students in the same semester. These courses are offered to second year students as a contingent learners' cohort who possessed the fundamental knowledge needed for the care of adult patients in the medical or surgical units. The nursing school offers a four-year Bachelor of Science in Nursing degree through a conventional program to high school graduates, and a bridging program to students having a two-year diploma. The overall number of students distributed over the four years of the program is 196 students. The training is carried out at a 240-bed hospital that is internationally accredited by the Joint Commission International Accreditation (JCIA) as a teaching facility. The preceptor model is used to guide students' clinical training and a clinical instructor from the school is responsible for overseeing their clinical experience in the individual units. Generally, the Clinical Assessment Form, a tool based on the Jordanian National Nursing Standards, is utilized to evaluate students' clinical performance in all clinical courses.

\subsection{Data collection methods and instruments}

Observation of Performance Aspects of Sound Clinical Judgment:

Clinical judgment is identified as a problem solving activity whereby a dilemma is identified and corrected. ${ }^{[9]}$ Petrina $^{[10]}$ identified four aspects of good problem solving, namely, engagement, background knowledge, process, and representation. Engagement refers to the extent to which a student identifies something as a problem and becomes engaged in solving it. Background knowledge refers to the extent to which a student accesses and uses appropriate information. Process refers to the extent to which a student understands and can use appropriate reasoning strategies free of biases in his/her clinical reasoning, which will result in appropriate clinical judgments/decisions, desired patient outcomes, and effective self-analysis and evaluation. Representation describes how effectively a student can communicate (verbally and in writing) his/her decision, solution or judgment; and the thinking and processes behind it to communicate effectively with patients, families and the health team. This includes how reflective the student is and how he/she critically evaluates nursing experiences. Based on Petrina's ${ }^{[10]}$ aspects of good problem solving, a 4-point SPACJS is developed (see Figure 1) to measure a student's clinical judgment

Published by Sciedu Press ability while providing or participating in the provision of nursing care to assigned clinical cases. The skill rating of the four aspects of clinical judgment is based on Lasater's ${ }^{[33]}$ assessment rubric. The Clinical Judgment Rubric is based on Tanner's ${ }^{[34]}$ Clinical Judgment Model that identified four aspects of clinical judgment, namely: noticing, interpreting, responding, and reflecting. Face validity of the scale was obtained from three course coordinators and five clinical instructors in the school. No changes were introduced to the English version of the scale. This version was used twice by the clinical instructors to assess students' clinical judgment ability at the beginning and at the end of the clinical courses. The assessment of the representation aspect of a good clinical judgment included assessing the quality of the student's documentation and its congruency with the student's oral representation of his/her clinical reasoning and judgment. The Data Action Response (DAR) documentation format was used by the students as a clinical judgment documentation tool. Training students in the use of this format was carried out at the beginning of the semester by the clinical instructors. The observations were carried out by means of the SPACJS during the second and the fourteenth week of the clinical rotation. A random hour per day, as part of the time sampling procedure, was allocated by the clinical instructors for the two observation days of each week. The observations documented clinical instructors' evaluations of students' performance aspects of clinical judgment.

Student demographics of age and gender, in addition to their Grade Point Average (GPA), were recorded by the clinical instructors at the time of the observation. Students were assured that their course clinical evaluations would not be affected if they opted to withdraw from the study. Withdrawal guaranteed omitting the two assessment episodes of a student's clinical judgment using the SPACJS, as well as their demographics, from the study data set. No withdrawals were reported.

\section{RESUlts}

The SPSS (version 20) statistical software was used to analyze the data. Data analysis was carried out to test the research hypothesis and document the effect of the blended pedagogies on students' clinical judgment performance aspects throughout adult health nursing courses.

Pretest results showed that male participants constituted two thirds of study subjects $(n=30)$ and nearly half of them $(n=$ 19) were aged between 20 and 21 years. Moreover, fifty-five percent $(n=22)$ of the subjects achieved a GPA between $60 \%$ and $69 \%$. Seven students had a GPA between $70 \%-75 \%$ and four students held a GPA above $80 \%$. Students' GPA is used generally to represent their accumulative achievement 
level in all courses. Hence, this study did not use the GPA as a post-test measure to indicate an improvement or a deterioration resulting from the implementation of the blended pedagogies but, rather, a variable that is subsequently correlated with the performance aspects of clinical judgment. All of the students who were observed in the two episodes of data collection were part of the conventional program.

$T$-test of paired samples was used to reveal what impact combining pedagogies has on clinical judgment performance aspects of junior nursing students. As shown in Table 1, the clinical instructors observed significant improvement in students' overall (total) performance aspects of clinical judgment $(-4.85, \alpha<0.001)$. Students showed improvement in the performance aspects of clinical judgment of background, process, and representation. This is indicated by the significant values of $t$-test of paired samples as shown in Table
1. Students' engagement in clinical judgment events was insignificant $(-1.856, \alpha=0.071)$ at the end of the semester, as indicated by clinical instructors' observations.

Pearson's product moment correlation coefficient was utilized to explore bonds between study variables. Table 2 shows significant relationships between the various performance aspects of clinical judgment. Each aspect strongly correlated with other aspects of clinical judgment at both the beginning and end of the clinical rotation.

Finally, two significant relationships among students' demographical variables were disclosed. Female students (n $=10)$ possessed better clinical judgment $(t=2.250$, sig. $=$ .035) than male students. Furthermore, the GPA of the students was positively correlated with the engagement aspect of clinical judgment $(r=0.369$, sig. $=.038)$.

Table 1. Performance aspects of clinical judgment

\begin{tabular}{|c|c|c|c|c|c|c|}
\hline \multirow{2}{*}{ Performance aspect of clinical judgment } & \multicolumn{2}{|c|}{ Pre } & \multicolumn{2}{|c|}{ Post } & \multirow{2}{*}{$t$-value } & \multirow{2}{*}{ Sig. $(2 \text {-tailed })^{*}$} \\
\hline & $\overline{\mathbf{x}}(\operatorname{Max}=4)$ & $\mathbf{S}$ & $\overline{\mathbf{x}}(\operatorname{Max}=4)$ & $\mathbf{S}$ & & \\
\hline Clinical judgment (ENGAGEMENT) & 2.5 & .68 & 2.8 & .84 & -1.856 & .071 \\
\hline Clinical judgment (BACKGROUND) & 2.3 & .75 & 2.7 & .82 & -4.523 & $<.001^{*}$ \\
\hline Clinical judgment (PROCESS) & 2.6 & .71 & 2.9 & .81 & -2.481 & $.018^{*}$ \\
\hline Clinical judgment (REPRESENTATION) & 2.2 & .72 & 2.9 & .66 & -6.607 & $<.001^{*}$ \\
\hline Total Clinical judgment & 59.5 & 15 & 70 & 17 & -4.85 & $<.001^{*}$ \\
\hline
\end{tabular}

Note. ${ }^{*}$ Significant at $.05 \alpha$ level

Table 2. Correlations between performance aspects of clinical judgment

\begin{tabular}{|c|c|c|c|c|c|c|c|c|c|}
\hline \multirow{2}{*}{ Variables } & & \multicolumn{2}{|c|}{ Engagement } & \multicolumn{2}{|c|}{ Background } & \multicolumn{2}{|c|}{ Process } & \multicolumn{2}{|c|}{ Representation } \\
\hline & & pre & post & pre & post & pre & post & pre & post \\
\hline \multirow{2}{*}{ Engagement } & pre & & & $\begin{array}{l}0.578^{* *} \\
(p<.001)\end{array}$ & & $\begin{array}{l}0.663^{* *} \\
(p<.001)\end{array}$ & & $\begin{array}{l}0.731^{* *} \\
(p<.001)\end{array}$ & \\
\hline & post & & & & $\begin{array}{l}0.572^{* *} \\
(p<.001)\end{array}$ & & $\begin{array}{l}0.727^{* *} \\
(p<.001)\end{array}$ & & $\begin{array}{l}0.682^{* *} \\
(p<.001)\end{array}$ \\
\hline \multirow{2}{*}{ Background } & pre & & & & & $\begin{array}{l}0.464^{* *} \\
(p<.003)\end{array}$ & & $\begin{array}{l}0.605^{* *} \\
(p<.001)\end{array}$ & \\
\hline & post & & & & & & $\begin{array}{l}0.608^{* *} \\
(p<.001)\end{array}$ & & $\begin{array}{l}0.668^{* *} \\
(p<.001)\end{array}$ \\
\hline \multirow{2}{*}{ Process } & pre & & & & & & & $\begin{array}{l}0.518^{* *} \\
(p<.001)\end{array}$ & \\
\hline & post & & & & & & & & $\begin{array}{l}0.688^{* *} \\
(p<.001)\end{array}$ \\
\hline
\end{tabular}

Note. ${ }^{* *}$ Correlations are significant at the .01 level (2-tailed)

\section{Discussion}

Combining concept-based and concept-mapping pedagogies impacted positively on students' performance aspects of clinical judgment throughout adult nursing courses. Except for the engagement aspect, students significantly improved in all of their performance aspects of clinical judgment. Engagement is operationally defined as the extent to which a student recognizes deviations in data and assertively becomes 
engaged in solving them as he/she reassesses the patient's condition, reports findings to the primary nurse, or monitors the patient's progress closely. The insignificant improvements in the engagement dimension of students' clinical judgment (mean changes from 2.5 to 2.8) might be attributed to students' attachment to the non-responsible pole where they exhibit a stagnated or withdrawn behavior. ${ }^{[35]}$ These insignificant improvements are similar to those reported by Lasater and Nielsen ${ }^{[19]}$ when considering the noticing phase of clinical judgment.

Lasater ${ }^{[33]}$ indicated that patients' problems are left unrecognized and no action is taken when the novice lacks noticing ability. This might be attributed to a novice's ignorance of the contextual cues and to his/her focus on technology, rather than the patient. ${ }^{[36]}$ Sedgwick et al. ${ }^{[13]}$ also implied that the bonds initiated by novices' with unit staff significantly affected their engagement in clinical reasoning and judgment encounters. Moreover, Hart and colleagues ${ }^{[6]}$ established that self-confidence of nurses affected their ability to identify deteriorating conditions and to intervene appropriately. Being contextually detached - especially from their patients and staff members and lacking the related confidence - will subsequently craft a novice's decision making or clinical judgment when responding to patient complaints and following protocols or documented care plans. ${ }^{[37]}$

Corrective efforts aimed at targeting students' engagement in clinical judgment should consider increasing students' awareness of the importance of this aspect of clinical judgment and its constituents that include recognizing subtle patterns in a patient's condition and then assuming responsibility even with complex, conflicting, or confusing data - by undertaking appropriate action, which may include reassessing the patient's condition, reporting the findings to the primary nurse, or closely monitoring the patient's progress. The literature indicated that nursing students need the necessary support to understand and articulate what they notice and to recognize its relevance. ${ }^{[34,38]}$ The clinical instructor can coach students throughout the clinical day while undertaking patient care responsibility and during the post-conference when debriefing and reflecting on daily encounters. Students' active engagement in these debriefings will enhance the "narrative-reflective" reasoning pattern, ${ }^{[32]}$ formally identified by Tanner ${ }^{[34]}$ as the "narrative" reasoning style. Students will reflect on the aspects of their clinical judgment, especially the engagement component, when listening to other students' stories. ${ }^{[32]}$ The transferal in clinical days will give the clinical instructor more room to redirect students' thinking towards the nuances of their observations and how these significant cues might connect with underlying pathophysiology. ${ }^{[23,39]}$ The deliberative discussions in the post-conferences will create the opportunity for students to explore choices on issues or core concepts related to nursing care ${ }^{[17]}$ - which will subsequently impact their performance aspects of clinical judgment.

Weekly feedback regarding the aspects of clinical judgment using the SPACJS which has been used in this study as a data collection tool will also help students reflect on their clinical judgment practices. Engagement in clinical judgment parallels what other authors have termed as "noticing". ${ }^{23,38]}$ Noticing is the ancestor for both clinical reasoning and clinical judgment. It is only possible when students link clinical experiences with formal learning and knowledge of the particular patient's patterns of responses. ${ }^{[38]}$ Poor attention to patients' needs and modest communication are the factors hampering these processes. ${ }^{[38]}$ Linking students with more experienced nurses who are able to effectively mentor or precept will add to the previous interventions. Preceptors can draw students' attention to not only the technical aspects of care, but also to the social and emotional subtleties that, when noticed, will prevent unnecessary patient suffering. ${ }^{[38]}$ This may require assigning students their own caseload, while maintaining their supernumerary status, rather than using them as nursing assistants. ${ }^{[0]}$ The effective preceptorship or clinical teaching strategies will subsequently strengthen deep thought processes to establish clinical judgment in nursing students. ${ }^{[41]}$ Having the appropriatemix of students within clinical groups (for example, considering students' GPA and gender), can also help in enhancing student engagement. While encouraging collaboration among students, the distribution of female students and those possessing higher GPA among the groups may help other students develop greater engagement with patients needs. This can be achieved by linking a female student or a student with higher GPA with a male student who possesses a lower GPA and then assigning the two students a room with two patients. Both students can collaborate in initiating relationships with patients and assuming responsibility and, at the same time, assess patients and identify significant cues. Reflecting together on these experiences can help students appreciate their achievements and focus on areas of improvement in relation to $\mathrm{CJ}$ aspects and processes.

The clinical instructor can also direct students' attention to the background, process, and representation aspects of clinical judgment as the results showed strong relationships between the four inextricably intertwined aspects of clinical judgment. This will subsequently enhance students' engagement ability - which is a prerequisite for compassionate, sensitive, and professional nursing action. ${ }^{[38]}$ 


\section{Conclusion}

Heims and Boyd ${ }^{[22]}$ advocated the utilization of research to document the efficacy of utilizing concept-based learning strategies in teaching clinical nursing. The current study contributes to that by documenting the impact of blending pedagogies to enhance students' clinical judgment skills. These student-centered approaches require the learner to construct knowledge essential to being able to analyze and critically think in every day practice. Despite demanding more preparation time than other approaches, the blended strategies are weaved to facilitate the move away from content laden teaching towards the construction of mental benchmarks to judge future patient encounters. The impact of these pedagogies can be maximized when the observation instrument used in the current study is utilized as an instructional aide. The SPACJS can provide faculty members with specific feedback regarding the performance of individual learners relating to the aspects of students' clinical judgment including engagement, background, process, and representation.

Institutionalizing both the blended teaching strategies and the SPACJS mandates formulating relevant policies, procedures and guidelines. Clinical instructors' feedback following students' reflections will help students attain professional maturity, take command of their clinical judgment, and have the ability to operate effectively in a changing and evolving practice environment.

Finally, further research is needed to include bridging students in studies with larger samples and extensions to other courses such as maternal or mental health nursing. Furthermore, the utilization of a control group in future research will be superior to the current basic design that guided the current study.

\section{ACKNOWLEDGeMents}

Amal Daghestani, PhD: Provided help relevant to the conception of the idea; Mahmoud Shahin, PhD: Preparing the background information related to some of the concepts and participated in data collection; Hadeel Monther, MSN: Preparing the background information related to some of the concepts and participated in data collection; Nadeen Ghabaen, MSN: Preparing the background information related to some of the concepts and participated in data collection; Tojan Adel, Bs: Preparing the background information related to some of the concepts and participated in data collection; Mohammad Haddad, Bs: Preparing the background information related to some of the concepts and participated in data collection; Chris O'Reilly: helped with the final drafting of this work.

\section{CONFLICTS OF INTEREST DisClosure}

The authors declare they have no conflicts of interest.

\section{REFERENCES}

[1] Buerhaus PI, Auerbach DI, Skinner LE, et al. State of the registered nurse workforce as a new era of health reform emerges. Nursing Economics. 2017; 35(5): 229-237.

[2] Glasper A. Will nursing shortages threaten the integrity and functioning of the NHS? British Journal of Nursing. 2016; 25(8): 458-459. PMid:27126755. https://doi.org/10.12968/bjon.2016.25. 8.458

[3] Goodare P. Literature review: why do we continue to lose our nurses? Australian Journal of Advanced Nursing. 2017; 34(4): 50-56.

[4] Snavely TM. A brief economic analysis of the looming nursing shortage in the United States. Nursing Economics. 2016; 34(2): 98-100. PMid:27265953.

[5] Harjai PK, Tiwari R. Model of critical diagnostic reasoning: Achieving expert clinician performance. Nursing Education Perspectives. 2009; 30(5): 305-311. PMid:19824241.

[6] Hart PL, Spiva L, Baio P, et al. Medical-surgical nurses' perceived self-confidence and leadership skills as first responders in acute patient deterioration events. Journal of Clinical Nursing. 2014; 23: 2769-2778. PMid:24393472. https://doi.org/10.1111/jocn .12523

[7] White AH. Clinical decision making among fourth-year nursing students: An interpretive study. Journal of Nursing Education. 2003; 42(3): 113-120. PMid:12661711.
[8] Levett-Jones T. Clinical reasoning: Learning to think like a nurse. Australia: Pearson; 2013.

[9] Sullivan E, Decker P. Effective leadership and management in nursing, 6th ed., New Jersey: Pearson/Prentice Hall; 2005.

[10] Petrina S. Advanced Teaching methods for the Technology Classroom. London, UK: Information Science Publishing; 2007. https : //doi.org/10.4018/978-1-59904-337-1

[11] Hart PL, Brannan JD, Long JM, et al. Using combined teaching modalities to enhance nursing students' recognition and response to clinical deterioration. Nursing Education Perspectives. 2015; 36(3): 194-196. https ://doi .org/10.5480/13-1083.1

[12] Saintsing D, Gibson L, Pennington A. The novice nurse and clinical decision making: how to avoid errors. Journal of Nursing Management. 2011; 19: 354-9. PMid:21507106. https ://doi .org/10.1 $111 / j .1365-2834.2011 .01248 . x$

[13] Sedgwick MG, Grigg L, Dersch S. Deepening the quality of clinical reasoning and decision-making in rural hospital nursing practice. The International Electronic Journal of Rural and Remote Health Research, Education, Practice and Policy. 2014.

[14] Doody O, Tuohy D, Deasy C. Final-year student nurses' perceptions of role transition. British Journal of Nursing. 2012; 21(11). https://doi.org/10.12968/bjon.2012.21.11.684

[15] Jahanpour F, Sharif F, Salsali M, et al. Clinical decision making in senior nursing students in Iran. International Journal of Nursing 
Practice. 2010; 16: 595-602. PMid:21129112. https://doi.org/ $10.1111 / j .1440-172 X .2010 .01886 . x$

[16] Cappelletti A, Engel JK, Prentice D. Systematic review of clinical judgment and reasoning in nursing. Journal of Nursing Education. 2014; 53(8): 453-458. PMid:25050560. https://doi.org/10.3 928/01484834-20140724-01

[17] De Menezes S, Correa C, Silva R, et al. Clinical reasoning in undergraduate nursing education: A scoping review. Journal of School of Nursing. 2015; 49(6): 1032-1039. https://doi.org/10.1590/ S0080-623420150000600021

[18] Telio S, Regehr G, Ajjawi R. Feedback and the educational alliance: examining credibility judgements and their consequences. Medical Education. 2016; 50: 933-942. PMid:27562893. https: //doi.org/10.1111/medu.13063

[19] Lasater K, Nielsen A. The influence of concept-based learning activities on students' clinical judgment development. Journal of Nursing Education. 2009; 48(8): 441-446. PMid:19681533. https : //doi.org/10.3928/01484834-20090518-04

[20] Wheeler L, Collins S. The influence of concept mapping on critical thinking in baccalaureate nursing students. Journal of Professional Nursing. 2003; 19(6): 339-346. https://doi.org/10.1016/S8 755-7223(03) 00134-0

[21] Mcgrath B. The development of concept-based learning approach as part of an integrative nursing curriculum. Whitireia Nursing and Health Journal. 2015; 22: 11-17.

[22] Heims M, Boyd S. Concept-based learning activities in clinical nursing education. Journal of Nursing Education. 1990; 29: 249-254. PMid:2165144.

[23] Nielsen A. Concept-based learning activities using the clinical judgment model as a foundation for clinical learning. Journal of Nursing Education. 2009; 48(6): 350-354. PMid:19552323. https: //doi.org/10.3928/01484834-20090515-09

[24] Nielsen A. Concept-based learning in the clinical environment. Doctoral dissertation, University of Northern Colorado; PhD 241 p-241 p. (1p). 2013.

[25] West EA. Constructivist theory and concept-based learning in professional nursing ethics: implications for nurse educators. Teaching Ethics. 2016; 16: 1, 121-130. https://doi.org/10.5840/tej2 01633129

[26] Gul R, Boman J. Concept mapping: A strategy for teaching and evaluation in nursing education. Nurse Education in Practice. 2006 6: 199-206. PMid:19040878. https://doi.org/10.1016/j.ne pr.2006.01.001

[27] Ca-as AJ, Reiska P, Möllits A. Developing higher-order thinking skills with concept mapping: A case of pedagogic frailty. Knowledge Management \& E-Learning. 2017; 9(3).

[28] Rochmawati E, Weichula R. Education strategies to foster health professional students' clinical reasoning skills. Nursing and Health
Sciences. 2010; 12: 244-250. PMid:20602698. https://doi .org/ $10.1111 / \mathrm{j} .1442-2018.2009 .00512 . \mathrm{x}$

[29] Gerdeman JL, Lux K, Jacko J. Using concept mapping to build clinical judgment skills. Nursing Education in Practice. 2013; 13(1): 11-17. PMid:22698820. https://doi.org/10.1016/j.nepr.2 012.05 .009

[30] Smith A, Lollar J, Mendenhall J, et al. Use of multiple pedagogies to promote confidence in triage decision making: A Pilot study. Journal of Emergency Nursing. 2012.

[31] Polit D, Beck C. Nursing research: Generating and assessing evidence for nursing practice, 9th ed., Philadelphia, USA: Walters Kluwer Health/Lippincott \& Williams \& Wilkins; 2012.

[32] Alfayoumi I. A contextual clinical reasoning model. Saarbrucken, Germany: Noor Publishing; 2017.

[33] Lasater K. Clinical judgment development: Using simulation to create an assessment rubric. Journal of Nursing Education. 2007; 46(11).

[34] Tanner C. Thinking Like a nurse: A Research-based model of clinical judgment in nursing. Journal of Nursing Education. 2006; 45(6): 204-212. PMid:16780008.

[35] Benner P, Tanner CA, Chesla CA. Expertise in nursing practice: Caring, clinical judgment and ethics. 2nd ed., New York: Springer Publishing Company; 2009. https : //doi .org/10.1891/978082 6125453

[36] Levett-Jones T, Hoffman K, Dempsey J, et al. The "five rights" of clinical reasoning: An educational model to enhance nursing students' ability to identify and manage clinically "at risk" patients. Nurse Education Today. 2010; 30: 515-520. PMid:19948370. https://doi.org/10.1016/j.nedt.2009.10.020

[37] Gillespie M, Paterson BL. Helping novice nurses make effective clinical decisions: The situated clinical decision making framework. Nursing Education Perspectives. 2009; 30(3): 164-170. PMid:19606659.

[38] Watson F, Rebair A. The art of noticing: essential to nursing practice. British Journal of Nursing. 2014; 23(10): 514-517. PMid:24851914. https://doi.org/10.12968/bjon.2014.23.10.514

[39] Lisko SA, O'Dell V. Integration of theory and practice: experiential learning theory and nursing education. Nursing Education Perspectives. 2010; 31(2): 106-108. PMid:20455368.

[40] Thomson R, Docherty A, Duffy R. Nursing students' experiences of mentorship in their final placement. British Journal of Nursing 2017; 26(9): 514-521. PMid:28493780. https ://doi.org/10.1 2968/bjon.2017.26.9.514

[41] Pouralizadeh M, Khankeh H, Ebadi A, et al. Factors influencing students' clinical judgment: A qualitative directed content analysis in an Iranian context. Journal of Clinical and Diagnostic Research. 2017; 11(5): 1-4. https://doi .org/10.7860/JCDR/2017/25753.98 22 